\title{
Ring out the old
}

\author{
Before letting go of the year 2021 completely, we highlight a very few of the important events it contained, both \\ global and personal, scientific and otherwise.
}

T his issue of Nature Plants marks the end of another year. It is a truism to say that the year just past has been a year like no other. Every twelve months is different and has particular highs and lows. We can hope that this will be the last year in which the COVID-19 pandemic makes in-person conferences if not completely impossible, then at least rare. But, at the time of writing, the increasing case numbers in many countries and the emergence of the B.1.1.529 variant in South Africa, now so prevalent that it has been dubbed the omicron variant, are making such optimism seem ill-founded.

Nevertheless, it is good to look back, however briefly, and celebrate some of the events of the year that is passing. From the point of view of research there have been many excellent studies published, both in Nature Plants and elsewhere. This is nothing unusual. Interesting and important research is published every week, often every day, making it impossible to identify it all. This month we have therefore produced a number of Year in Review items on papers that have caught the attention of the Nature Plants editors over the last 12 months. We hope that they will lead you to some studies you might otherwise have missed.

There has been substantial political focus on agriculture and by extension on plant biology in 2021. The 26th United Nations Climate Change Conference of the Parties (COP26) held in Glasgow, UK, at the beginning of November resulted in pledges to shift to more sustainable farming practices, to reduce methane emissions ( $32 \%$ of which come from agriculture) by
$30 \%$ over the next decade, and to halt and potentially reverse the current rate of global deforestation.

Before this, however, the first United Nations Food Systems Summit was held in New York on 23 and 24 September. This brought together scientists, policymakers and industry, resulting in the establishment of initiatives around five 'action areas' (https://foodsystems. community/commitment-registry/), focussed on nourishing all people; boosting nature-based solutions of production; building resilience to vulnerabilities, shocks, and stresses; advancing equitable livelihoods, decent work \& empowered communities; and establishing means of implementing such initiatives. What the ultimate effect of all these good intentions will require much more than a single year to assess (https://www.nature.com/articles/ s43016-021-00401-x).

2021 also saw the loss of some eminent plant researchers. Probably the most renowned of these was Yuan Longping, often said to be China's most famous scientist (https://www.nature.com/articles/ s41477-021-00962-6). His development of breeding techniques based on a detailed understanding of plant genetics increased rice yields by around $20 \%$ and helped alleviate China's food shortages in the 1970s, earning him the nickname 'the father of hybrid rice.' Another departee was the chemical ecologist Jean Langenheim, who worked for much of her career at the University of California, Santa Cruz. In the 1960s Langenheim showed that amber was not the product of pine tree resin, as had been presumed, but from a tropical flowering tree; she went on to be the leading expert on all aspects of plant resins.

There have been a number of changes for Nature Plants itself. In October our long-time editor Lei Lei left for a new publishing role. This will be the first change in our editorial team in more than five years. Almost her last task was to chair a session at the Nature conference 'Harnessing the Plant Microbiome' (https://conferences. nature.com/event/5f53e7f8-a89a-4a43-bb97d6092145b0fa/summary) hosted by the University of California, Davis, which she had been instrumental in organising. We wish her every success in her new endeavours.

This has also been our first year as a transformative journal with the ability to offer Open Access publication for any research paper. Since the first of January we have published 13 research papers Open Access (a little under 10\% of our total), and we hope to see this number increase over time. We do want to state, though, that no author will be prevented from publishing with us due to lack of resources to cover the article processing charges associated with Open Access publication. Also, this can have no influence on our editorial decisions as such information is completely hidden from the journal's editors.

Having taken a little time to look back over 2021, it is time to turn towards the new year. There is much to look forward to in 2022, most particularly the new and unexpected discoveries that it will undoubtedly contain.

Published online: 14 December 2021 https://doi.org/10.1038/s41477-021-01072-z 